\title{
БУРОНАБИВНЫЕ СВАИ С УШИРЕННЫМ ОСНОВАНИЕМ - ДОСТОЙНАЯ АЛЬТЕРНАТИВА ЗАБИВНЫМ СВАЯМ
}

\section{В. П.Чернюк ${ }^{1}$, С. М. Семенюк², В. И. Юськович ${ }^{3}$, Е. И. Шляхова}

\author{
${ }^{1}$ К. т. н., доцент, доцент кафредры технологии строительного производства \\ учреждения образования «Брестский государственный технический университет», Брест, Беларусь \\ ${ }^{2}$ К. т. н., доцент, декан строительного фракультета учреждения образования \\ «Брестский государственный технический университет», Брест, Беларусь \\ ${ }^{3}$ K. т. н., доцент, заведующий кафредрой технологии строительного производства \\ учреждения образования «Брестский государственный технический университет», Брест, Беларусь \\ ${ }^{4}$ Старший преподаватель кафредры технологии строительного производства \\ учреждения образования «Брестский государственный технический универсuтет», Брест, Беларусь, e-mail: Katusha_bstu@mail.ru
}

\section{Реферат}

В статье приведены преимущества буронабивных свай с уширениями перед аналогичными сваями без уширений и недостатки забивных свай. Основные достоинства таких свай сводятся к повышенной несущей способности по грунту основания при минимальном расходе бетона на их изготовление. Приведены прогрессивные конструкции устройств и приспособлений для образования уширений в забое скважин, защищенные патентами на изобретения и полезные модели РБ, а также а.с. СССР, и опубликованные за рубежом. Дан расчет несущей способности таких свай по грунту основания в связи с его отсутствием в отечественной нормативной литературе.

Ключевые слова: буронабивная свая, уширение, достоинство, недостатки, несущая способность, расход бетона, технические разработки, патенты, изобретения.

\section{BORED PILES WITH A WIDE BASE - A WORTHY ALTERNATIVE TO DRIVEN PILES}

\section{Abstract}

\section{P. Chernuk, S. M. Semianiuk, V. I. Yuskovich, E. I. Shlyahova}

The article presents the advantages of bored piles with broadening over similar piles without broadening and the disadvantages of driven piles. The main advantages of such piles are reduced to increased bearing capacity on the soil of the base and the minimum consumption of concrete for their manufacture. The progressive design of devices and devices for the formation of broadening in the bottom of the wells, protected by patents for inventions and utility models of the Republic of Belarus, as well as A.S. USSR, and published abroad. The calculation of the bearing capacity of such piles on the ground soil due to its absence in the domestic regulatory literature.

Keywords: bored pile, broadening, dignity, disadvantages, bearing capacity, concrete consumption, technical developments, patents, inventions.

\section{Введение}

В настоящее время в строительной отрасли проектируется большое количество мостов, эстакад, зданий и сооружений на забивных сваях. Использование забивных свай считается дешевым способом строительства фундаментов, однако он не всегда применим. Их применение сопровождается большим количеством сложностей и затруднений при устройстве таких свайных фундаментов.

Можно выделить основные недостатки забивных свай:

- низкая несущая способность свай по грунту основания, достигающая лишь 600-1000 кH;

- ограниченная длина забивных свай, как правило, не превышающая 10-15 м. Устройство более длинных свай требует стыковки двух отдельных свай (модульных) и создает большую сложность их качественной забивки в грунт;

- ограниченная возможность устройства забивных свай в городской черте из-за шума и вибрации, превосходящих допустимые их уровни (50-70 дБ) в 2-2,5 раза и достигающих уровня порядка 120-140 дБ. В развитых западноевропейских странах (Великобритании, Франции и др.) забивка свай и использование их в строительных целях запрещены законом по причинам экологии, охраны труда, сохранения исторических ценностей и др.;

- сваи эффективны только при массовом их количестве в фундаменте, измеряемых сотнями и тысячами единиц;

- забивные сваи часто повреждаются при их погружении, следовательно требуются дополнительные затраты денежных средств на ликвидацию последствий;

- отсутствие заводов, производящих забивные сваи в данном регионе, что существенно увеличивает стоимость работ за счет транспортных расходов;

- повышенная стоимость применения забивных свай в сельской местности из-за отсутствия сваебойной техники и самих свай по сравнению с городскими условиями, а так же дополнительные транспортные расходы на их доставку.

\section{Основная часть}

Для совершенствования свайных фундаментов и создания альтернативы забивным сваям авторами был проанализирован зарубежный и отечественный опыт устройства буронабивных свай. Основным направлением была выбрана разработка технологии устройства буронабивных свай с уширенным основанием или с уширенной пятой. Эта технология разрабатывалась в расчете на массовое устройство свай в сложных геологических условиях (в слабых глинистых или песчаных грунтах, в том числе водонасыщенных). Технический результат заключался в создании высокотехнологичных способов сооружения свай с уширением (пятой), обеспечивающих значительную несущую способность свай в грунте основания и достижение экономического эффректа.

Наиболее широко применяемая в строительстве забивная свая имеет размер ствола $a \times b=0,3 \times 0,3 \mathrm{~m}$, а площадь ее опирания на грунт составляет $A=0,3 \times 0,3=0,09 \mathrm{~m}^{2}$. Такая же буронабивная свая, но с уширением на нижнем конце (пятой) диаметром Д всего лишь 0,6 м, имеет площадь опирания на грунт $A=3,14 \times 0,6^{2} / 4=0,283$ м² $^{2}$. Следовательно, данная буронабивная свая с уширением имеет преимущество перед забивной сваей по площади опирания на грунт в 0,283/0,9 = 3,14 раза. Таким образом, несущая способность буронабивной сваи $\mathrm{F}$ по грунту основания с небольшой пятой превосходит несущую способность, как минимум в три раза, не считая в обоих случаях сопротивлений сдвигу по их боковым поверхностям.

Уширение сваи существенно увеличивает не только несущую способность сваи $F$, но и значительно экономит удельный расход бетона в $м^{3}$ на 1 тонну несущей способности, то есть $V / F$, вследствие малого объема бетона в пяте, величина которого составляет $\mathrm{V}=\frac{\pi \times Д^{3}}{6}=\frac{3,14 \times 0,6^{3}}{6}=0,113 \mathrm{M}^{3}$, то есть чуть больше $0,1 \mathrm{~m}^{3}$. Техническая и экономическая целесообразность устройства фундаментов на буронабивных сваях с уширенной пятой несомненна, вследствие значительного увеличения их несущей способности $F$, сокращения времени на устройство и экономии затраченного материала (бетона).

В мировой практике разработаны различные способы образования уширений под такие буронабивные сваи (с пятой). Это буронабивные сваи с уширениями, разбуриваемыми специальными уширителями механического действия, однако они сложны по конструкции [1]. 
Известны способы создания уширений взрывом (Магадан, Воркута), но они весьма опасны и не всегда применимы (камуфолетные сваи) [2]. Применяются способы образования уплотненных ядер ударами (вытрамбованные сваи), но это требует использования дорогостоящей, но малоэффрективной техники (Россия) [3]. В Беларуси разработаны, но мало применяются выштампованные сваи, частично похожие на вытрамбованные, сложность применения которых заключается в узкой области использования и трудности извлечения штампов и трамбовок из грунтов [3].

Авторами предложено более полусотни разработок для образования уширений, пят, уширенных оснований, уплотненных ядер и зон как в забое, так и в стенках скважин, все они защищены 70 патентами Республики Беларусь и РФ на изобретения и полезные модели, а также авторскими свидетельствами СССР. Значительная их часть наиболее эфффективных и работоспособных в применении, обладающих новизной, полезностью и существенными отличиями (в изобретательском и техническом плане) опубликованы в монографиях и учебных пособиях за рубежом (в Германии и России) $[4,5,6]$, а несколько простых и прогрессивных разработок показаны на рисунке 1.
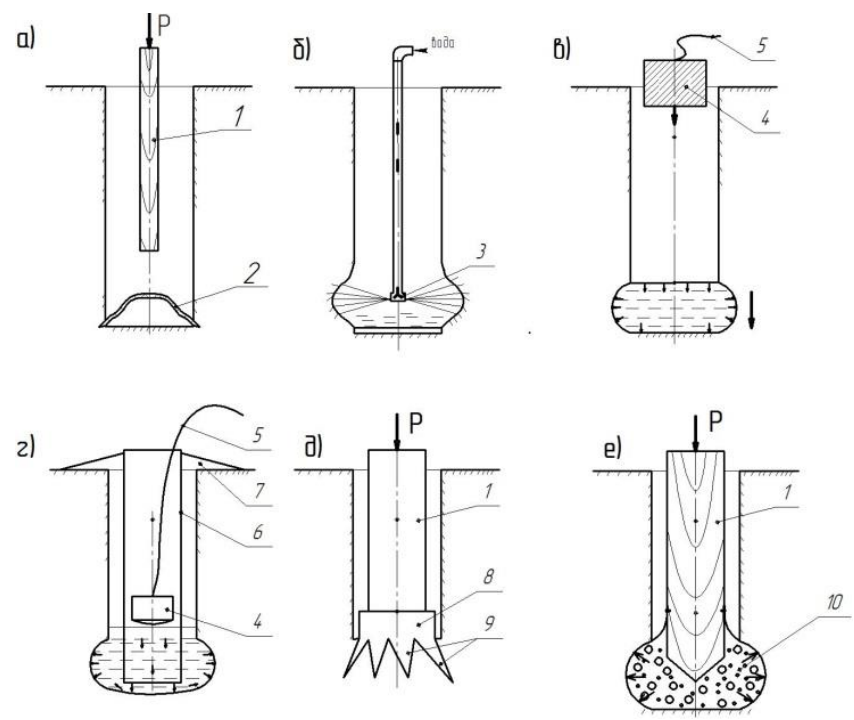

1 - шток; 2 - изогнутая заостренная по краям пластина;

3 - размывное устрой-ство (гидромонитор); 4 - подвесной ударный груз; 5 - гибкая (веревочная, проволочная или тросовая) тяга;

6 - труба; 7 - открылки; 8 - уширитель стаканного типа;

9 - пилообразные зубья; 10 - бетонная смесь, щебень, гравий, галька

Рисунок 1 - Прогрессивные конструкции устройств и приспособлений для образования укреплений в забое скважин

Предоставленные на данном рисунке технические предложения позволяют образовывать уширения, уширенные основания и пяту в забое скважин путем:

- выпрямления в скважине штоком предварительно изогнутой и опущенной в нее пластины (патенты РБ на изобретения №№ 9410, 14968 и на полезную модель № 5631, рисунок 1 «а»);

- размыва стенок скважины в забое водой размывным устройством: вантус, гидромонитора (патенты РБ на изобретения №№ 8700,9160 , рисунок 1 «б»);

- падения на воду в скважине подвесного груза (патент Республики Беларусь на изобретение № 8712, рисунок 1 «в»);

- падения по направляющей штанге или в трубе на воду в скважине груза (патенты РБ не полезные модели №№ 8917, 12196, рисунок 1 «г»);

- раскрытия в забое скважины штоком уширителя стаканного типа С зубьями пилообразной формы (патенты РБ на изобретение № 9185 и полезную модель № 4869, рисунок 1 «д»);

- втрамбовывания штоком бетонной смеси в забой скважинь щебня, гравия, гальки в мешке или без него (патент РБ на полезную модель № 5283, рисунок 1 «е»);

- взрывания в забое скважины зарядов ВВ с применением безопасной катушки (патент РБ на полезную модель № 6937);
- использования электромагнитного уширителя в виде тора (a.c. СССР № 1745859);

- вмятия в забой или стенки скважины U - образной пластины (патент Республики Беларусь на полезную модель № 6277);

- деформации уширителя беличьего типа (патент Республики Беларусь на полезную модель № 7465);

- трамбования якорной цепи (патент Республики Беларусь на полезную модель № 9782);

- раздвижки в забое скважин конусом или клином специальных элементов, шаров, тел (патенты Республики Беларусь на полезные модели №№ 2081, 11041, 11343, 5309, 6868, а.с. СССР № 1177437); - другими способами (патенты Республики Беларусь на полезные модели №№ 7703, 12061, 12218).

Большинство из указанных и представленных на рисунке 1 устройств для образования уширений в скважинах обладают простой конструкцией и технологичностью производства работ. Некоторые из них успешно прошли модельные, лабораторные и производственные испытания и готовятся к внедрению в условиях белорусского региона.

После устройства уширений в скважинах могут устанавливаться арматурные каркасы и вместе со скважинами заполняться бетонной смесью и уплотняться, например трамбовками. В результате чего после затвердевания бетонной смеси в грунте образуются полноценные буронабивные сваи с уширенной пятой.

Аналогичные конструкции свай за рубежом начали применяться более века тому назад и в качестве фундаментных конструкций (опор) достаточно широко применяются и в настоящее время, только под другими названиями (сваи Страуса, "Беното", “Франки”, частотрамбованные, вибронабивные, пневмонабивные, камуфрлетные, вытрамбованные и выштампованные).

Для устройства таких свай требуются специальная техника и технологии. Буронабивные сваи с уширенной пятой используются в строительстве таких развитых стран как Япония, Китай, США, Великобритания, Франция, в том числе в России (например, при строительстве Крымского моста) и в Беларуси (при строительстве теплиц в Минской области).

Расчет несущей способности буронабивных свай с уширениями по грунту основания может быть выполнен согласно пособия П13-01 к СНБ 5.01.01-99 [7] по формуле:

$$
F_{d}=\gamma_{c}\left(\gamma_{c R} \cdot R \cdot A+U \sum \gamma_{c f} \cdot f_{i} \cdot h_{i}\right)
$$

где $\gamma_{\text {c }}$ - коэффициент условий работы сваи; в случае опирания ее на пылевато-глинистые грунты со степенью влажности менее $S_{r}<0.9, \gamma_{\mathrm{c}}=0.8$, а в остальных случаях $\gamma_{\mathrm{c}}=1$;

$\gamma_{C R}-$ коэфффициент условий работы грунта под нижним концом сваи;

$\gamma_{C R}=1$ во всех случаях, за исключением свай с уширением, бетонируемым подводным способом, для которых $\gamma_{C R}=0,9$, а также опор воздушных линий электропередач, для которых коэффициент $\left(\gamma_{C R}\right)$ принимается по отдельным указаниям;

$R$ - расчетное сопротивление грунта, под нижним концом сваи, кПа, принимаемое по указаниям п. 5.8.1 [7];

$A$ - площадь опирания сваи на грунт, $M^{2}$, принимаемая для буронабивных свай и свай с уширением, равной площади поперечного сечения уширения в месте наибольшего его диаметра;

$U$ - периметр поперечного сечения ствола сваи, м;

$\gamma_{c f}$ - коэффициент условий работы грунта на боковой поверхности сваи, зависящий от способа образования скважины и условий бетонирования, принимаемый по таблице 5.15 [7];

$f_{i}$ - расчетное сопротивление для середины $i$-го слоя грунта на боковой поверхности ствола сваи, кПа, принимаемое по таблице 2 [7];

$h_{i}$ - толщине $i$-го слоя грунта, соприкасающегося с боковой поверхностью сваи, м. 
Вестник Брестского государственного технического университета. 2021

При расчете $\mathrm{F}$ по формуле (1) могут возникнуть трудности в определении площади опирания уширения сваи А на грунт из-за сложности замера на глубине диаметра (Д) уширения (рис. 1 «б, в, г, е»). Для устранения этих проблем авторы предлагают рассчитывать А по формулам, а не замерять на глубине. Считая уширение в скважине шарообразным или близким к нему (в других случаях остальное идет в запас прочности), Д и А рассчитываются по формулам (2), (3)

$$
\begin{aligned}
& Д=\sqrt[3]{\frac{6 \Delta V}{\pi}} \\
& A=\frac{\pi Д^{2}}{4},
\end{aligned}
$$

где Д- диаметр уширения, м;

$\Delta V=V-V_{C}$ объём уширения, $\mathrm{M}^{3}$;

$V_{c}=\frac{\pi d^{2}}{4} H$ - объем скважины (без уширения), м³;

$H$ - глубина скважины (без уширения), м;

$d$ - диаметр скважины, м;

$V$ - фактически замеренный и уложенный в скважину объем бетона (вместе с уширением), м $^{3}$;

$A$ - площадь уширения, м².

Например, при $d=0,3 \mathrm{~m}, H=10 \mathrm{~m}, V_{c}=\frac{3,14}{4} * 0,3^{2 *} 10=0,7065 \mathrm{~m}^{3}$.

Если замеренный в бадье, уложенный и уплотненный в скважине с уширением объем бетона равен $V=0,85 \mathrm{~m}^{3}$, то объем уширения составит $\Delta V=0,85-0,7065=0,1435 \mathrm{~m}^{3}, Д=\sqrt[3]{\frac{6 * 0,1435}{\pi 3,14}}=\sqrt[3]{0,274} \approx 0,65 \mathrm{~m}$ а $A=\frac{3,14^{*} 0,65^{2}}{4}=0,33 \mathrm{~m}^{2}$. Площадь опирания сваи без уширения на грунт $F$ равна площади поперечного сечения скважины и она равна $F=\frac{3.14}{4} \cdot 0.3^{2}=0.071 \mathrm{M}^{2}$.

Следовательно, площадь уширения (пяты) превышает площадь скважины в $\frac{A}{F}=\frac{0,33}{0.071}=4,6$ раза. Примерно во столько же раз несущая способность данной сваи с уширением превышает несущую способность сваи без уширения или забивной сваи.

\section{Заключение}

Использование буронабивных свай с уширениями или уширенными основаниями в фундаментостроении по сравнению $c$ аналогичными буронабивными сваями (без уширений и уширенных оснований) и забивными позволяет повысить их несущую способность по грунту основания в несколько раз при значительном сокращении удельного расхода бетона и других материалов. Энергоэффрективные и технологичные способы бурения скважин и образования уширений в грунте для этого имеются.

\section{Список цитированных источников}

1. Ягудин, А. М. Буронабивные сваи с лучевидными уширениями / А. М. Ягудин. - Саратов : Издательство Саратовского университета, 1983. - 168 с.

2. Кречин, А. С. Ресурсосберегающие фундаменты на сельских стройках / А. С. Кречин [и др.]. - Кишинев : Картя Молдовеняскэ, 1990. -247 c.

3. Чернюк, В. П. Расчет, проектирование и устройство свайных фундаментов / В. П. Чернюк, П. С. Пойта. - Брест : Облтипография, 1998. - $216 \mathrm{C}$.

4. Чернюк, В. П. Производство свайных работ в особых условиях / В. П. Чернюк, П. П. Ивасюк. - Германия : LAP LAMBEPT Publishing, 2016. $-196 \mathrm{c}$.

5. Чернюк, В. П. Технология свайных работ в особых условиях строительства: учебное пособие / В. П. Чернюк, Е. И. Шляхова. М. : 000 «РУСАИНС», 2019. - $241 \mathrm{c}$.

6. Чернюк, В. П. Технологические свойства и способы бурения скважин с уширениями в строительстве и горном деле: учебное пособие / В. П. Чернюк, Е. И. Шляхова. - М. : ООО «РУСАЙНС», 2020. - $140 \mathrm{C}$.

7. Проектирование и устройство буронабивных свай: П13-01 к СНБ 5.01.01-99. - Минск: Министерство архитектуры и строительства Республики Беларусь, 2002. - 43 с.

\section{References}

1. Yagudin, A. M. Buronabivnye svai s luchevidnymi ushireniyami / A. M. Yagudin. - Saratov : Izdatel'stvo Saratovskogo universiteta, 1983. - $168 \mathrm{~s}$.

2. Krechin, A. S. Resursosberegayushchie fundamenty na sel'skih strojkah / A. S. Krechin [i dr.]. - Kishinev : Kartya Moldovenyaske, 1990. $-247 \mathrm{~s}$.

3. Chernyuk, V. P. Raschet, proektirovanie i ustrojstvo svajnyh fundamentov / V. P. Chernyuk, P. S. Pojta. - Brest : Obltipografiya, 1998. $-216 \mathrm{~s}$.

4. CHernyuk, V. P. Proizvodstvo svajnyh rabot v osobyh usloviyah / V. P. Chernyuk, P. P. Ivasyuk. - Germaniya : LAP LAMBEPT Publishing, 2016. - $196 \mathrm{~s}$.

5. CHernyuk, V. P. Tekhnologiya svajnyh rabot $v$ osobyh usloviyah stroitel'stva: uchebnoe posobie / V. P. Chernyuk, E. I. Shlyahova. M. : 000 «RUSAJNS», 2019. - $241 \mathrm{~s}$.

6. CHernyuk, V. P. Tekhnologicheskie svojstva i sposoby bureniya skvazhin $s$ ushireniyami $v$ stroitel'stve i gornom dele: uchebnoe posobie / V. P. Chernyuk, E. I. Shlyahova. - M. : 000 «RUSAJNS», 2020. $-140 \mathrm{~s}$.

7. Proektirovanie i ustrojstvo buronabivnyh svaj: P13-01 k SNB 5.01.01-99. Minsk: Ministerstvo arhitektury i stroitel'stva Respubliki Belarus', 2002. $-43 \mathrm{~s}$.

Материал поступил в редакцию 06.05.2021 